\title{
Impact of Home Fitness Program on Anthropological Characteristics of Physically Active and Physically Inactive People
}

\author{
Gordana Furjan-Mandic', Biljana Bilbija', Josipa Radas'1, Gordana Ivkovic ${ }^{2}$ \\ 'University of Zagreb, Faculty of Kinesiology, Zagreb, Croatia, ${ }^{2}$ University of Zadar, Centre for Gymnastics and Student Sports, Zadar, Croatia
}

\section{Abstract}

Main purpose of this work is presentation of a complex program that consists of simple program content focusing towards targeted change of important anthropological characteristics. To achieve the objective, authors created "stay at home" fitness program with simple exercise content which is adjusted for both trainees based on their fitness level. The sample is defined as a pattern of two trainees. One exerciser is male and physically inactive and the other is female and physically active. The initial and final state of the subjects is determined with 4 tests for assessment of morphological characteristics and 6 tests for assessment of motor abilities. For comparison of the measured results of the initial and final state of the respondents we used the method of calculating the difference expressed as a percentage, using the "Microsoft Excel". After completing treatment, we've observed positive changes in all measures for the assessment of anthropological status, for trained and untrained persons.
\end{abstract}

Key words: fitness, female, male, anthropological characteristics

\section{Introduction}

Studies in countries across Europe show low levels of overall physical activity of different populations. Degree of health is one of the main determinants of the level of life quality. Sedentary lifestyle causes reduction of physical activity and thus leads to a threat to public health and normal functioning of one's organs and organ systems (Hollmann \& Hettinger, 2000).

Results of previous studies haves shown that regular, properly planned and programmed physical exercise has a positive impact on high blood pressure (Faggard \& Tipton, 1994), blood fat levels (Berg, Frey, Baumstark, Halle, \& Keul, 1994) and elevated body mass index (Mišigoj-Duraković, Heimer, Gredelj, Heimer, \& Sorić, 2007). However, regardless of the fact that physical exercise has beneficial effects on human health, there is still a relatively small number of people who continuously engage in recreational physical exercise.

Main purpose of this work is presentation of a complex program that consists of simple program content focusing towards targeted change of important anthropological charac- teristics. To achieve this objective, authors created a "stay at home" fitness program with simple exercise content which is adjusted for both trainees based on their fitness level.

Fitness activity can be divided into two groups: health-related fitness and skill-related fitness (Oja \& Tuxworth, 1995). A Home fitness program implies a collection of training contents which can be executed in living spaces, such as a house or an apartment. It is suitable for use to exercisers of all fitness levels. This type of program is not intended for exercisers which have not overcome technique of execution of all elements planned for carrying out the program and elementary knowledge about dosage of energy-related components of training load. All contents have to be chosen by a kinesiologist or other qualified individual, such as a physiotherapist or a doctor. Otherwise, exercisers could suffer from an acute or chronic injury which would have a negative impact on performance and motivation of exercisers during training, or could even lead to drastic reduction and even to withdrawal from physical activities during their free time.

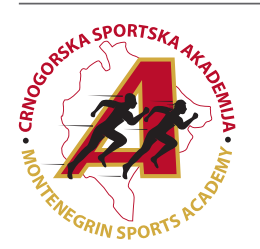

Correspondence: 
Home fitness program can be executed:

- independently

- under trainer or other qualified individual surveillance

- in pair or in a small group

- with an audio or video projection

\section{Advantages of a home fitness program}

Training execution at home has many advantages of which the most prominent one is accessibility to exercisers of all ages, financial state, gender and fitness level because it does not demand a specially arranged space of large dimensions, numerous props and equipment which can be expensive and complicated to use. That form of training is highly attractive for people who do not have free time, and by training at home they conserve time needed for travelling to and from a fitness center. In addition, it is suitable for all those that do not prefer crowded places and noise. Also, there are exercisers that feel uncomfortable when training in front of other people or trainers because they are insecure with their appearance or abilities, and familiar space offers them security.

\section{Disadvantages of a home fitness program}

Primary disadvantage of execution of a home program is training without surveillance of a qualified individual. Because of that reason, this program is not recommended for beginners and people who have not acquired a high level of automated movement structures needed for execution of a certain training. Moreover, people who decide to implement this program need to be acquainted with training load dosage. These processes can be demotivating and negatively influence health status of exercisers who are not qualified for proper training execution.

\section{Methods}

The sample is defined as a pattern of two trainees. One exerciser is male and physically inactive and the other is female and physically active.

\section{Physically active exerciser}

Date of birth: 28.1.1987.

Gender: female

Profession classification: belongs to group C and D.

Daily routine is characterized by dynamic responsibilities dominated by activities in which walking and weight carrying prevail, and subject belongs to employees with high energy consumption. In addition to everything that was specified, subject was involved in professional sport activities for 15 years until she injured her knee, after which she has undergone a surgical procedure (two years before execution of the program).

\section{Physically inactive exerciser}

Date of birth: 28.1.1987

Gender: male

Profession classification: belongs to group A and $\mathrm{B}$.

Daily routine is characterized by static responsibilities dominated by standing and sitting positions and those positions also prevail during his free time. Subject was never involved in sports, or any other type of continuous, organized recreational physical activity, and was never a participant of a fitness program.

\section{Description of executed fitness program}

Fitness in not a sport, recreation or rehabilitation; fitness is a specific approach to a healthy lifestyle through sport, recreation and rehabilitation, which is realized with physical activities, rest and nutrition, considering gender, age, fitness and other characteristics (Nićin, 2003; custom translation).

Home fitness program contains simple program contents which are available and adapted to exercisers and their different levels of adoption of training knowledge, different levels of functional and motor abilities and completely different requirements on their workplace.

Duration of training process is in a period of two months, that is, nine weeks (Table 1). It is important to emphasize that selection of training contents and training load is focused on alteration of morphological characteristics of exercisers, and on development of specific motor abilities, primarily because of effects on health, and improvement of level of working abilities.

Primary goal of the program is reduction of subcutaneous fatty tissue and increase of power, primarily core muscles. Both exercisers have conducted equal program contents with adapted absolute load in relation to individual characteristics and fitness level, but with approximately equal relative load during the whole period.

Beside subcutaneous fatty tissue reduction, program is focused on development of power of bigger muscle groups in arms and shoulder region, core muscles and lower extremity muscles, and improvement of functional abilities.

This complex program consists of simple movement structures, aerobics dance steps, strength exercises with exercisers own weight, strength exercises with a prop (one weight of 4 kilograms, two dumbbells of 1 kilogram, wheel with handles, exercise mat), stretching and muscle relaxation exercises.

For purposes of main A and B part in which circular methodical form was conducted, a program that generates a sound every 30 seconds with which a change of contents during exercise is announced was used. Besides parts of the program where aerobics steps were used, where music is a mandatory segment (120-130 bpm), it is advisable to use music through the whole training because it has a positive effect on motivation of exerciser and helps in rhythmic execution of exercises.

\section{Duration of program}

As mentioned before, home fitness program for achieving effects occurs in a period of two months (Table 1). Overall number of days planned for actualizing the program is 61 days. Number of training days and days needed for conducting diagnostics of condition within that period is 42 days $(39+3)$, and 19 days of rest. Number of training days per week gradually increases, with first week having 3 training days, from second to sixth week 5 training days are conducted, and during the last week, 6 training days are conducted. Every training day consists of only one training, with duration progressively increasing throughout the program.

Training duration is 45 minutes in first three weeks, then subsequently 60 minutes ( 1 hour) until the last week and 70 minutes in the last week ( 1 hour and 10 minutes).

Initial and final state of the subjects is determined with 4 tests for assessment of morphological characteristics and 6 tests for assessment of motor abilities. Tests for evaluation of morphological characteristics: 
Table 1. Display of training days per week and in total

\begin{tabular}{lc}
\hline Duration of training period & $01.04-01.06 .2015$ \\
\hline Weeks with 3 trainings & 1 \\
Weeks with 4 trainings & 4 \\
Weeks with 5 trainings & 2 \\
Weeks with 6 trainings & 1 \\
Total number of weeks & 9 \\
Total number of training days & 39 \\
Number of days for diagnostics & 3 \\
\hline
\end{tabular}

- Body mass- measured with home scale

- Percentage of fatty tissue - evaluated with Omron BF306 device

- Circumference: chest, waist, stomach, hips, upper leg, lower leg, upper arm, forearm - measured with tailor meter

- Body mass index - (BMI) was calculated directly on the basis of recorded values of body mass and height, with the formula BMI=body mass $(\mathrm{kg}) /$ body height $\left(\mathrm{m}^{2}\right)$.

Tests for evaluation of motor abilities:

- Execution of push-ups in 15 seconds - for evaluation of repetitive strength of arms and shoulder region

- Lying leg raises, repetitions until exhaustion- for evaluation of anterior core muscle power

- Wall squat test, on time measured until exhaustion for evaluation of static strength of leg muscles

- Lying trunk extension hold, time measured until exhaustion - for evaluation of static strength of back muscles

- Hold in plank position with support on elbows ("plank")- for evaluation of static strength of muscles responsible for torso stabilization
- In kneeling position, frontally, rolling of wheel with handles away and towards self on the floor until exhaustion - for evaluation of repetitive strength of muscles responsible for torso stabilization

For comparison of measured results of initial and final state of the respondents we used the method of calculating the difference expressed as a percentage, using "Microsoft Excel".

\section{Results}

Besides the noticeable improvement in execution of all tests after the program has finished, trainees have advanced the most in tests which required a certain type of strength which is not specific for their professions (Table 2).

Physically active exerciser had a less noticeable improvement in tests 1 (push-ups/15 sec) and 6 (lying trunk extension), because she falls into a group of dynamic professions where weight carrying is represented, and those topological regions have a certain level of strength already on a higher level.

Physically inactive exerciser had a less noticeable improvement in the test for evaluation of strength of lower extremities/ test No. 5 (wall squat), because it falls into a group of static professions where standing is a dominant activity.

Table 3 displays differences of individual and final testing expressed with a percentage which displays how much subjects have advanced in individual motor tests. Results show that subjects have achieved advancement in execution of all tests for strength evaluation which were used for evaluation of state of subjects in this paper.

Morphological characteristics were not displayed in percentages, because almost all scales of measurement and measurement units are equal, so the advancement of subjects can be noticed with inspection of initial and final state in Table 2.

Table 2. Display of initial, transit and final state of both subjects

\begin{tabular}{|c|c|c|c|c|c|c|}
\hline \multirow[b]{2}{*}{ date } & \multicolumn{3}{|c|}{ physically inactive exerciser } & \multicolumn{3}{|c|}{ physically active exerciser } \\
\hline & 1.4.2015. & 1.5.2015 & 1.6.2015. & 1.4.2015. & 1.5.2015. & 1.6.2015. \\
\hline measurement & initial & transit & final & initial & transit & final \\
\hline body mass index & 23.7 & 23.1 & 22.7 & 23.6 & 23.0 & 22.3 \\
\hline body mass & $79.5 \mathrm{~kg}$ & $77.4 \mathrm{~kg}$ & $76.0 \mathrm{~kg}$ & $66.5 \mathrm{~kg}$ & $65.0 \mathrm{~kg}$ & $62.5 \mathrm{~kg}$ \\
\hline$\%$ fatty tissue & $17.2 \%$ & $16.9 \%$ & $15.0 \%$ & $21.0 \%$ & $19.9 \%$ & $19.2 \%$ \\
\hline chest circumference & $96.1 \mathrm{~cm}$ & $98.0 \mathrm{~cm}$ & $95.2 \mathrm{~cm}$ & $93.0 \mathrm{~cm}$ & $91.2 \mathrm{~cm}$ & $89.2 \mathrm{~cm}$ \\
\hline waist circumference & $86.6 \mathrm{~cm}$ & $86.0 \mathrm{~cm}$ & $84.3 \mathrm{~cm}$ & $74.3 \mathrm{~cm}$ & $73.0 \mathrm{~cm}$ & $70.0 \mathrm{~cm}$ \\
\hline stomach circumference & $92.3 \mathrm{~cm}$ & $90.0 \mathrm{~cm}$ & $88.5 \mathrm{~cm}$ & $82.5 \mathrm{~cm}$ & $80.0 \mathrm{~cm}$ & $77.5 \mathrm{~cm}$ \\
\hline upper leg circumference & $57.5 \mathrm{~cm}$ & $58.0 \mathrm{~cm}$ & $57.0 \mathrm{~cm}$ & $61.0 \mathrm{~cm}$ & $60.0 \mathrm{~cm}$ & $60.0 \mathrm{~cm}$ \\
\hline lower leg circumference & $38.1 \mathrm{~cm}$ & $37.5 \mathrm{~cm}$ & $38.0 \mathrm{~cm}$ & $36.0 \mathrm{~cm}$ & $36.0 \mathrm{~cm}$ & $36.5 \mathrm{~cm}$ \\
\hline upper arm circumference & $33.0 \mathrm{~cm}$ & $32.6 \mathrm{~cm}$ & $34.5 \mathrm{~cm}$ & $29.2 \mathrm{~cm}$ & $29.5 \mathrm{~cm}$ & $28.5 \mathrm{~cm}$ \\
\hline forearm circumference & $28.5 \mathrm{~cm}$ & $27.5 \mathrm{~cm}$ & $27.5 \mathrm{~cm}$ & $25.0 \mathrm{~cm}$ & $25.5 \mathrm{~cm}$ & $24.5 \mathrm{~cm}$ \\
\hline hips circumference & $102.2 \mathrm{~cm}$ & $100.5 \mathrm{~cm}$ & $99.7 \mathrm{~cm}$ & $101.0 \mathrm{~cm}$ & $99.2 \mathrm{~cm}$ & $98.0 \mathrm{~cm}$ \\
\hline push-ups/15 sec & $11 x$ & $16 x$ & $20 x$ & $16 x$ & $18 x$ & $18 x$ \\
\hline wheel (repetition) & $10 x$ & $17 x$ & $25 x$ & $7 x$ & $21 x$ & $34 x$ \\
\hline lying leg raises & $16 x$ & $32 x$ & $48 x$ & $25 x$ & $35 x$ & $64 x$ \\
\hline plank & $41 \mathrm{sec}$. & 1:28 min. & 1:52 min. & $57 \mathrm{sec}$. & $1: 20 \mathrm{~min}$. & 2:14 min. \\
\hline wall squat & $34 \mathrm{sec}$. & $2: 46 \min$. & $3: 23$ min. & 1:35 min. & 3:45 min. & 6:31 $\mathrm{min}$. \\
\hline lying trunk extension & $45 \mathrm{sec}$. & $1: 30 \mathrm{~min}$. & 2:11 min. & $55 \mathrm{sec}$. & $1: 30 \mathrm{~min}$. & 2:14 min. \\
\hline
\end{tabular}


Table 3. Display of acquired results of motor tests expressed in percentages

\begin{tabular}{lcc}
\hline \multicolumn{1}{c}{ motor tests } & $\begin{array}{c}\text { physically } \\
\text { inactive } \\
\text { exerciser }\end{array}$ & $\begin{array}{c}\text { physically } \\
\text { active } \\
\text { exerciser }\end{array}$ \\
\hline push-ups in 15 seconds & $82 \%$ & $12,5 \%$ \\
wheel & $150 \%$ & $385 \%$ \\
lying leg raises & $200 \%$ & $156 \%$ \\
plank & $173 \%$ & $135 \%$ \\
wall squat & $497 \%$ & $311 \%$ \\
lying trunk extension & $191 \%$ & $143 \%$ \\
\hline
\end{tabular}

\section{Discussion}

After completing the treatment, positive changes have been observed in all measures used for assessment of anthropological status, for trained and untrained subjects.

Changes are mainly related to decrease in percentage of body fat, volume of specific body parts and to improve results in certain tests for physical abilities of physically active or inactive trainee to primarily improve their health, and secondly to get their training abilities to higher levels of performance.

In physically active trainees, whose normal day is dominated by physical activity (work in the fitness center) a very small progress of $12.5 \%$ in development of power of arms and shoulders (test: number of push-ups in 15 seconds) was measured, while with physically inactive trainees, ones with professions with no physical activity, impressive improvement of $82 \%$ compared to the initial state was measured. Then, in evaluation of static strength of lower extremities (endurance in squat position against the wall) with physically inactive trainees, who when carrying out daily duties are mostly in standing position, an improvement of $497 \%$ was measured, which is much lower than in physically active exercisers who achieved improvement of $311 \%$. Home fitness program has achieved visible effects that show improvement of the status of active and inactive trainees.

Applying the planned content of physical exercise has shown improvement in power of different topological regions that are essential for daily performance of interest, especially for those who were less active on a daily basis.

Because of difficult everyday obligations, both trainees felt tiredness, and often also pain in different areas of body, caused by peculiarities of their professions. After the conducted exercise program at home, pain has disappeared, and discomfort and tiredness have gradually decreased. Achieved effects of conducted training process confirm that it is necessary to exercise in free time to increase operational capabilities and improve health status for the purpose of performing work related obligations more easily, and therefore self-content feeling. Noticeable effects which indicate improvement of condition of active and inactive subject have been achieved with the home fitness program. Improvement in various topological regions which are important for everyday performance in professions has been achieved with the use of program contents, especially for improvement of those topological regions which are less active during everyday obligations. Results have also shown that subcutaneous fatty tissue has been successfully reduced in both subjects, which in overall shows efficiency of the "Home fitness program", and that the goal of this paper is satisfied and realized.

\section{Acknowledgements}

There are no acknowledgements.

\section{Conflict of Interest}

The authors declare there are no conflict of interest.

Received: 06 June 2017| Accepted: 08 July 2017

\section{References}

Anderson, B. Pearl, B., \& Bruke, E. (1994). Getting in Shape: Shelter Publications, Inc.

Andrijašević, M. (2000). Rekreacijom do zdravlja. Fakultet za fizičku kulturu sveučilišta u Zagrebu.

Berg, A., Frey, I., Baumstark, M.V., Halle, M., \& Keul, J. (1994). Physical activity and lipoprotein disorders. Sports Med, 17, 6-21.

Faggard, R.H., \& Tipton, C.M. (1994). Physical activity, fitness and hypertension. U: Physical activity, fitness and health. Champain IL: Human Kinetics.

Hollmann, W., \& Hettinger, T. (2000). Sportmedizin. Grundlagen für Arbeit, Training und Präventivmedizin. Stuttgart-New York: Schattauer.

Marković, G. (2008). Strength and power in sports: definition, determinants, machinery, customization and training. Zagreb: Faculty of Kinesiology: Association of Croatian fitness trainers.

Mišigoj-Duraković, M., Heimer, S., Gredelj, M., Heimer, Ž., \& Sorić, M. (2007). Physical inactivity in Croatia. Acta Medica Croatica, 61, 253-258.

Nićin, Đ. (2003). Fitness. Fakultet za menadžment u sportu univerziteta "Braća Karić", Beograd.

Oja, P., \& Tuxworth, B. (1995). Eurofit for adults. Assessment of health-related fitness. Tampere, Finland: Council of Europe. 